\title{
Improved detection of metastatic lymph nodes in oesophageal squamous cell carcinoma by combined interpretation of fluorine-18-fluorodeoxyglucose positron- emission tomography/computed tomography
}

Ji Young Lee ${ }^{1 \dagger}$, Young Hwan Kim² ${ }^{2+}$, Yong-Jin Park ${ }^{3}$, Soo Bin Park ${ }^{4}$, Hyun Woo Chung ${ }^{5}$, Jae II Zo ${ }^{6}$, Young Mog Shim ${ }^{6}$, Kyung Soo Lee ${ }^{7}$ and Joon Young Choi ${ }^{3^{*}}$ (D)

\begin{abstract}
Background: We sought to evaluate the diagnostic performance of fluorine-18-fluorodeoxyglucose positron-emission tomography/computed tomography $\left({ }^{18} \mathrm{~F}-\mathrm{FDG}\right.$ PET/CT) in the detection of metastatic lymph nodes by combined interpretation of PET/CT images in patients with oesophageal squamous cell carcinoma.

Methods: Two hundred three patients with oesophageal squamous cell carcinoma underwent ${ }^{18} \mathrm{~F}$-FDG PET/CT before oesophagectomy and lymph node dissection. Maximum standardized uptake value (SUV max), mean Hounsfield unit $(\mathrm{HU})$, short axis diameter (size), and visual CT attenuation (high, iso-, low) were evaluated on noncontrast CT and PET images following PET/CT scan. In this combined interpretation protocol, the high attenuated lymph nodes were considered benign, even if the $S U V_{\max }$ value was high. The diagnostic accuracy of each method was compared using the postoperative histologic result as a reference standard.
\end{abstract}

Results: A total of 1099 nodal stations were dissected and 949 nodal stations were proven to demonstrate metastasis. $\mathrm{SUV}_{\max }$ and size of the malignant lymph nodes were higher than those of the benign nodes, and visual $\mathrm{CT}$ attenuation was significantly different among the two groups $(P<0.001)$. Using cutoff values of 2.6 for $S U V_{\max }$ and $10.2 \mathrm{~mm}$ for size, the combined interpretation of an $S U V_{\max }$ of more than 2.6 with iso- or low $C T$ attenuation [area under the curve (AUC): 0.846 , 95\% confidence interval (Cl): 0.824-0.867] showed significantly better diagnostic performance for detecting malignant lymph nodes than SUV $\max$ only (AUC: 0.791, 95\% Cl: $0.766-0.815$ ) and size (AUC: $0.693,95 \%$ Cl: $0.665-0.720)$ methods $(P<0.001)$ in a receiver operating characteristic curve analysis.

Conclusions: The diagnostic accuracy of PET/CT for nodal metastasis in oesophageal squamous cell carcinoma was improved by the combined interpretation of ${ }^{18} \mathrm{~F}-\mathrm{FDG}$ uptake and visual $\mathrm{CT}$ attenuation pattern.

Keywords: ${ }^{18}$ F-FDG, PET/CT, Oesophageal cancer, Lymph node metastasis, SUV $V_{\text {max }}$ CT attenuation

\footnotetext{
*Correspondence: jynm.choi@samsung.com

${ }^{\dagger} \mathrm{Ji}$ Young Lee and Young Hwan Kim contributed equally to this work.

${ }^{3}$ Department of Nuclear Medicine, Samsung Medical Center, Sungkyunkwan

University School of Medicine, 81 Irwon-ro, Gangnam-gu, Seoul 06351,

Republic of Korea

Full list of author information is available at the end of the article
}

(C) The Author(s). 2019 Open Access This article is distributed under the terms of the Creative Commons Attribution 4.0 International License (http://creativecommons.org/licenses/by/4.0/), which permits unrestricted use, distribution, and reproduction in any medium, provided you give appropriate credit to the original author(s) and the source, provide a link to the Creative Commons license, and indicate if changes were made. The Creative Commons Public Domain Dedication waiver (http://creativecommons.org/publicdomain/zero/1.0/) applies to the data made available in this article, unless otherwise stated. 


\section{Background}

Oesophageal cancer is the sixth most common cause of cancer-related mortality worldwide, leading to $3.2 \%$ of all deaths $[1,2]$. The two most common histologic types found in more than $95 \%$ of all oesophageal cancer are squamous cell carcinoma (SCC) and adenocarcinoma. In particular, the SCC type has dominated for most of the twentieth century, particularly in Asian countries [3]. Surgical resection is the standard treatment approach for patients with early oesophageal cancer $[4,5]$. Because the stage of oesophageal cancer is strongly associated with appropriate treatment options and its prognosis, accurate determination of clinical staging is essential. In particular, lymph node staging in oesophageal cancer is an important independent prognostic factor that can affect the surgical extent of lymph node dissection and the long-term survival of patients [6-10].

Lymph node metastasis in oesophageal cancer occur early and quickly to adjacent or regional lymph nodes because of the submucosal lymphatic drainage system of the oesophagus [11]. In cases of early-stage SCC, lymph node involvement is more widely distributed and the rates of metastatic lymph nodes are higher versus in those in adenocarcinoma $[12,13]$. In a previous study, the prevalence of nodal metastasis differed significantly between SCC and adenocarcinoma cases (36\% vs. 21\%) in early oesophageal cancer [13]. Therefore, accurate lymph node staging is important in oesophageal carcinoma, especially in early-stage SCC.

For initial staging including the detection of nodal metastasis, fluorine-18-fluorodeoxyglucose ( $\left.{ }^{18} \mathrm{~F}-\mathrm{FDG}\right)$ positron emission tomography/computed tomography (PET/CT) has been widely used in patients with oesophageal cancer in recent years [14-17]. However, the results about the accuracy of regional nodal metastasis on ${ }^{18} \mathrm{~F}$-FDG PET/CT are controversial, with relatively low sensitivity. Furthermore, in tuberculosis endemic areas, specificity for nodal staging has been reported to be reduced due to false-positive FDG-avid lymph nodes in oesophageal cancer $[14,18]$. In several previous reports, mediastinal lymph nodes that show increased FDG uptake on PET images but high attenuation and/or calcification on the CT component of a PET/CT scan had a high probability for benign node in lung cancer $[19,20]$. In other words, the combined interpretation of PET/CT images was helpful to improve the specificity for detecting metastatic lymph nodes in lung cancer. Recently, the usefulness of both measurements of X-ray attenuation taken from unenhanced CT images and FDG uptake in the PET/CT of lymph node metastasis in oesophageal cancer was reported [21]. However, this study was somewhat limited by its relatively small size and ambiguity of the PET criteria due to evaluation by visual analysis.

Therefore, the aim of this study was to evaluate the diagnostic performance of ${ }^{18} \mathrm{~F}$-FDG PET/CT in detecting metastatic lymph nodes via the combined interpretation of PET/CT images in patients with oesophageal squamous cell carcinoma. Optimal PET/CT criteria for detecting metastatic lymph nodes were also investigated.

\section{Methods \\ Patients}

After this study was approved by the relevant Institutional Review Board (IRB no. 2019-03-129), the medical records of 479 consecutive patients with biopsy-proven oesophageal SCC who underwent ${ }^{18}$ F-FDG PET/CT for preoperative staging at our institute were retrospectively reviewed. Patients who underwent preoperative neoadjuvant chemotherapy or concurrent chemoradiation before surgery were excluded $(n=273)$. Also, three patients were excluded due to PET/CT data error. Finally, 203 patients who received oesophagectomy with lymph node dissection after PET/CT were finally included in this study. Recorded intervals between PET/CT scan and surgery ranged from one to 70 days (average $14 \pm 10$ days). Two patients had double primary cancer, specifically sigmoid colon and stomach cancer with a pathologic cell type of adenocarcinoma. Chest CT showed findings suggesting stable tuberculosis in 27 patients (13.3\%).

\section{${ }^{18}$ F-FDG PET/CT}

Patients were fasted for at least 6 hours before the ${ }^{18}$ F-FDG PET/CT scan. Blood glucose levels before the injection of ${ }^{18} \mathrm{~F}$-FDG were lower than $200 \mathrm{mg} / \mathrm{dL}$ in all patients. PET/ CT imaging was performed using a dedicated PET/CT scanner (Discovery LS; GE Healthcare, Marlborough, MA, USA), without intravenous or oral contrast material.

Using the GE Discovery LS device (eight-slice helical CT scanner), a whole-body CT scan was obtained, using a continuous spiral technique (140 keV, 40-100 mA adjusted for the patient's weight, section width of $5 \mathrm{~mm}$ ), at $60 \mathrm{~min}$ after the injection of ${ }^{18}$ F-FDG $(5.5 \mathrm{MBq} / \mathrm{kg})$. After the CT scan, an emission scan from mid-thigh to the basal skull area was obtained for 4 minutes per frame in a twodimensional mode. Attenuation-corrected PET images (voxel size: $4.3 \times 4.3 \times 3.9 \mathrm{~mm}$ ) were reconstructed from the CT data, using an ordered-subset expectation maximization algorithm (28 subsets, two iterations). Attenuation-corrected torso PET/CT images were reviewed using the commercial software (GE Advantage Workstation; GE Healthcare, Marlborough, MA, USA).

\section{Image analysis}

${ }^{18}$ F-FDG PET/CT images were retrospectively reviewed by two experienced nuclear medicine physicians, who were unaware of the clinical and pathological results, on a dedicated workstation by consensus. Lymph nodes were classified into 15-group nodal stations according to a modified lymph node mapping system for oesophageal 
cancer [22]. After determining the region of interest (ROI) of lymph nodes in the noncontrast CT image, the same size ROI was applied to the PET image. The physicians measured size (short axis diameter) and obtained the parameters of the mean Hounsfield unit (HU) and the maximum standardized uptake value $\left(\mathrm{SUV}_{\max }\right)$ of each lymph node using a ROI-based measurement on the noncontrast CT component and PET images from the PET/CT scan. By visual analysis of the noncontrast CT images of PET/CT, lymph nodes were classified into three groups, as follows: 1) lymph nodes with high attenuation, which had higher attenuation than that in the surrounding great vessels with (superior vena cava, ascending thoracic aorta and aortic arch) mediastinal window images or definite calcifications; 2) lymph nodes with iso-attenuation, which had similar attenuation to that that in the surrounding great vessels; and 3) lymph nodes with low attenuation, which had lower attenuation than that in the surrounding great vessels. In the combined interpretation of noncontrast CT component and FDG uptake on ${ }^{18}$ F-FDG PET/CT, benign lymph nodes were defined as those with high attenuation or calcification on noncontrast CT images, even if the $\mathrm{SUV}_{\max }$ was higher than a cutoff value.

\section{Surgery and pathology}

Transthoracic oesophagectomy and extensive lymph node dissection were performed by experienced thoracic surgeons. They dissected all visible and palpable lymph nodes in the surgical field after considering the results of preoperative imaging modalities including ${ }^{18}$ F-FDG PET/CT. Each dissected lymph node group was labelled according to a modified lymph node mapping system for oesophageal cancer [22]. Specimens were stained with haematoxylin and eosin and examined with optical light microscopy.

\section{Statistical analysis}

Statistical analyses were performed using the Statistical Package for the Social Sciences version 22.0 (IBM Corp., Armonk, NY, USA) and the MedCalc version 14.8.1 (MedCalc Software, Mariakerke, Belgium). The histopathology of the surgical specimen was the gold standard to which the results of the imaging methods were compared and the accuracy of detecting lymph node involvement was calculated. To compare the PET and noncontrast CT parameters for benign and malignant lymph nodes, a Student's t-test for continuous variables and the chi-squared test for categorical ones were used. Sensitivity, specificity, positive predictive values (PPVs), and negative predictive values (NPVs) were calculated for methods of PET/CT examinations on a lesion-perlesion basis and were compared with outcomes of McNemar's test. The predictive value of LN metastasis was measured via area under the curve (AUC) in a receiver operating characteristic (ROC) curve analysis, and the optimal cutoff values for detecting individual metastatic lymph nodes were determined. Differences were considered statistically significant when $P$ values were less than 0.05 .

\section{Results \\ Lymph node histology}

The patients' characteristics are summarized in Table 1. A total of 1099 nodal stations were sampled in 203 patients (mean number of nodal stations sampled per patient: 5.4). Of these lymph nodes, 150 lymph nodes (13.6\%) in 97 patients (47.8\%) proved to be positive for malignancy. The metastasis sites were one of two lower cervical paratracheal (nodal station 1), 53 of 185 upper paratracheal (2), one of five prevascular and retrotracheal (3), none of 24 lower paratracheal (4), two of 100 aortopulmonary (5), 18 of 191 subcarinal (7), 18 of 38 thoracic paraesophageal (8), six of 130 pulmonary ligament (9), five of 68 tracheobronchial (10), two of 21 diaphragmatic (15), 16 of 72 paracardial (16), 17 of 112 left gastric (17), two of 65 common hepatic (18), one of one splenic (19), and eight of 85 celiac (20) nodes according to pathologic examination.

\section{Comparisons of lymph node groups}

When we examined the parameters of PET/CT scan in benign and malignant lymph node groups, the size and $\mathrm{SUV}_{\text {max }}$ of individual lymph nodes were significantly higher in the malignant lymph node group than in the benign group $(P<0.001)$. In the visual analysis of noncontrast $\mathrm{CT}$ attenuation, there were significant differences in low attenuation, iso-attenuation, and high attenuation and/or calcification between the benign and

Table 1 Patient characteristics

\begin{tabular}{ll}
\hline Characteristics & Value \\
\hline Age (years) & $63 \pm 8$ \\
Gender (male) & $194(95.6)$ \\
Locations & \\
Upper thoracic & $14(6.9)$ \\
Middle thoracic & $58(28.6)$ \\
Lower thoracic & $118(58.1)$ \\
Upper to mid-thoracic & $1(0.5)$ \\
Mid to lower thoracic & $12(5.9)$ \\
Histologic grade & \\
$\quad$ Well-differentiated & $41(20.2)$ \\
Moderate & $108(53.2)$ \\
Poor & $21(10.3)$ \\
$\quad$ Undetermined & $33(16.3)$ \\
Total & 203 \\
\hline
\end{tabular}

Data are presented as mean \pm standard deviation or $\mathrm{n}(\%)$ 
malignant lymph node groups $(P<0.001)$. The mean HU on noncontrast CT component was not statistically different between the groups (Table 2).

\section{Diagnostic performance of individual node assessment for single modality}

From the ROC analysis, the optimal cutoff points for $\mathrm{SUV}_{\max }$ and size distinguishing benign from metastatic lymph nodes were 2.6 and $10.2 \mathrm{~mm}$. The sensitivity and accuracy of an $\mathrm{SUV}_{\max }$ of more than 2.6 for the detection of metastatic lymph nodes was significantly higher than those of size more than $10.2 \mathrm{~mm}$, as follows: sensitivity of $72.7 \%(109 / 150)$ vs. $55.3 \%(83 / 150)$ and accuracy of $75.6 \%(831 / 1099)$ vs. $72.2 \%$ (793/1099), respectively $(P \leq 0.001)$. Although the specificity of $\mathrm{SUV}_{\max }$-only assessment was higher than that of size measurement (76.1\% [722/949] vs. $74.8 \%$ [710/949]), the difference was not statistically significant $(P=0.476)$ (Table 3$)$.

By visual analysis on noncontrast CT component, the sensitivity, specificity, and accuracy of attenuation patterns were $98.0 \%$ (147/150), 17.8\% (159/949), and 28.8\% (793/1099). In the visual CT attenuation analysis, the sensitivity was significantly higher than the methods of $\mathrm{SUV}_{\max }$ and size evaluation $(P<0.001)$, while the specificity and accuracy were significantly lower than those methods $(P<0.001)$ (Table 3$)$.

With ROC curve analysis, the diagnostic performance of $\mathrm{SUV}_{\max }$ with a cutoff value of 2.6 [AUC: $0.791,95 \%$ confidence interval (CI): 0.766-0.815] for distinguishing benign from metastatic nodes was significantly better than that of size with a cutoff value of $10.2 \mathrm{~mm}$ (AUC: 0.693, 95\% CI: 0.665-0.720), respectively $(P<0.001)$.

\section{Combined interpretation of PET/CT images}

For the combined interpretation of PET/CT images, 172 lymph nodes with visually high attenuation were

Table 2 Comparisons of lymph nodes between benign and malignant groups

\begin{tabular}{|c|c|c|c|}
\hline & $\begin{array}{l}\text { Benign } \\
(n=949)\end{array}$ & $\begin{array}{l}\text { Malignant } \\
(n=150)\end{array}$ & $P$ value \\
\hline Size by $\mathrm{CT}(\mathrm{mm})$ & $\begin{array}{l}8.4 \pm 3.0 \\
(2.2-22.7)\end{array}$ & $\begin{array}{l}11.1 \pm 4.5 \\
(4.4-36.87)\end{array}$ & $<0.001$ \\
\hline$S U V_{\max }$ & $\begin{array}{l}2.2 \pm 1.2 \\
(0.6-8.9)\end{array}$ & $\begin{array}{l}4.5 \pm 3.0 \\
(0.8-16.6)\end{array}$ & $<0.001$ \\
\hline $\begin{array}{l}\text { CT attenuation } \\
\text { pattern (visual) }\end{array}$ & & & $<0.001$ \\
\hline Low attenuation & 472 & 73 & \\
\hline Iso attenuation & 308 & 74 & \\
\hline $\begin{array}{l}\text { High attenuation } \\
\text { and/or calcification }\end{array}$ & 169 & 3 & \\
\hline $\mathrm{CT}$ attenuation & $59.1 \pm 66.0$ & $58.2 \pm 21.7$ & 0.87 \\
\hline
\end{tabular}

CT computed tomography, SUV $V_{\max }$ Maximum standardized uptake value Data are presented as mean \pm standard deviation (min-max), number or mean \pm standard deviation
Table 3 Diagnostic performance for detecting regional lymph node metastasis

\begin{tabular}{llllll}
\hline & $\begin{array}{l}\text { Sensitivity } \\
(\%)\end{array}$ & $\begin{array}{l}\text { Specificity } \\
(\%)\end{array}$ & PPV (\%) & NPV (\%) & $\begin{array}{l}\text { Accuracy } \\
(\%)\end{array}$ \\
\hline SUV $_{\max }>2.6^{\mathrm{a}}$ & 72.7 & $76.1(74.9-$ & 32.4 & 94.6 & 75.6 \\
& $(65.4-$ & $77.1)$ & $(29.2-$ & $(93.2-$ & $(73.6-$ \\
& $79.1)^{\mathrm{b}}$ & & $35.3)$ & $95.9)$ & $77.4)$ \\
Size $>10.2 \mathrm{~mm}^{\mathrm{a}}$ & 55.3 & $74.8(73.6-$ & 25.8 & 91.4 & 72.2 \\
& $(47.7-62.7)$ & $76.0)$ & $(22.2-$ & $(89.9-$ & $(70.1-$ \\
& & & $29.2)$ & $92.8)$ & $74.2)$ \\
CT attenuation & 98.0 & $17.8(17.2-$ & 15.9 & 98.3 & 28.8 \\
pattern (visual) & $(94.0-99.5)$ & $18.0)$ & $(15.2-$ & $(94.7-$ & $(27.7-$ \\
& & & $16.1)$ & $99.5)$ & $29.2)$ \\
\hline
\end{tabular}

$C T$ computed tomography, NPV negative predictive value, $P P V$ positive predictive value, $S U V_{\max }$ Maximum standardized uptake value

${ }^{a}$ Data were evaluated using cutoff value from ROC analysis

${ }^{\mathrm{b}}$ Numbers in parentheses are $95 \%$ confidence intervals

Sensitivity: SUV $V_{\max }$ Vs. size, $P=0.001$; SUV $_{\max }$ Vs. $C T$ attenuation pattern, $P<$ 0.001 ; size vs. $C T$ attenuation pattern, $P<0.001$

Specificity: SUV max $_{\max }$ vs. size, $P=0.476$; $\mathrm{SUV}_{\max }$ Vs. $C T$ attenuation pattern, $P<$ 0.001 ; size vs. $C T$ attenuation pattern, $P<0.001$

Accuracy: SUV max $_{\text {vs. size, } P<0.001 \text {; SUV }}$ max Vs. CT attenuation pattern, $P<$ 0.001 ; size vs. $C T$ attenuation pattern, $P<0.001$

converted to benign. The greatest test accuracy was obtained by selecting a cutoff value of $\mathrm{SUV}_{\max }$ of 2.6 (AUC: $0.846,95 \%$ CI: $0.824-0.867 ; P<0.001$ ) with a sensitivity of $70.7 \%(104 / 150)$, specificity of $86.7 \%$ (823/ 949), and accuracy of $84.5 \%$ (929/1099), respectively (Table 4). In the combined interpretation of PET/CT images, the sensitivity was decreased as compared with in $\mathrm{SUV}_{\max }$-only evaluation, but there was no significant difference between the two methods $(P=0.25)$. Additionally, the specificity and accuracy were significantly improved in the combined interpretation method versus in the single assessment methods $(P<0.001)$. A comparison of the obtained ROC curves showed a significant statistical difference in AUC among the combined interpretation of $\mathrm{SUV}_{\max }$ of more than 2.6 with iso- and low attenuation and $\mathrm{SUV}_{\max }$ of more than 2.6 only and size measurement $(P<0.001)$ (Fig. 1$)$.

\section{Discussion}

We performed a study to determine the diagnostic performance of ${ }^{18} \mathrm{~F}$-FDG PET/CT in the detection of individual lymph node metastasis in patients with oesophageal SCC. The combined interpretation of $\mathrm{SUV}_{\max }$ on PET images with $\mathrm{CT}$ attenuation on noncontrast $\mathrm{CT}$ component was more accurate than that single assessment of $\mathrm{SUV}_{\max }$, size, or CT attenuation of PET/CT images. When lymph node status determined by $\mathrm{SUV}_{\max }$ was more than 2.6 with iso-attenuation or low attenuation on noncontrast CT images, the accuracy was improved in detecting individual lymph node metastasis in patients with oesophageal SCC (Fig. 2). The specificity was also increased in the combined interpretation of $\mathrm{PET} / \mathrm{CT}$ images compared to the single evaluated methods, although sensitivity was decreased. 
Table 4 Diagnostic performance of combined interpretation of PET/CT images

\begin{tabular}{llllll}
\hline & Sensitivity (\%) & Specificity (\%) & PPV (\%) & NPV (\%) & Accuracy (\%) \\
\hline SUV $_{\max }>2.6^{\text {a }}$ with iso- or low CT attenuation & $70.7(63.6-77.0)^{\mathrm{b}}$ & $86.7(85.6-87.7)$ & $45.7(41.1-49.8)$ & $94.9(93.7-96.0)$ & $84.5(82.6-86.3)$
\end{tabular}

CT computed tomography, NPV negative predictive value, $P E T$-CT positron-emission tomography/computed tomography, $P P V$ positive predictive value, SUV $V_{\text {max }}$ Maximum standardized uptake value

${ }^{a}$ Data were evaluated using cutoff value from ROC analysis

${ }^{b}$ Numbers in parentheses are $95 \%$ confidence intervals

Lymph node involvement in oesophageal cancer has a great impact on both treatment decision and prognosis of the patient. To detect such lymph node metastasis of the patient diagnosed by oesophageal cancer, pretreatment evaluations have used many modalities including endoscopic ultrasonography (EUS), chest $\mathrm{CT}$, and ${ }^{18} \mathrm{~F}$-FDG PET/CT. Meta-analysis studies have revealed that EUS is the most sensitive of these options, whereas CT and FDG PET are more specific tests for the detection of regional lymph node metastasis but overall offer similar diagnostic performance [23, 24]. EUS has limitations for evaluating the nodal status of oesophageal cancer patients with the presence of stenosis or strictures, which may affect low accuracy and nodal overstaging. In addition, interobserver variation and machine-dependent factors may exist and patient cooperation is essential for safe and successful EUS practice [25].

Chest CT is the most commonly used imaging technique for the staging of oesophageal cancer and helps to evaluate lymph nodes dependent on size criteria. Because the criteria of enlarged lymph nodes vary according to anatomical location and the detection of metastasis in normal-sized lymph nodes, the sensitivity and specificity of nodal metastasis assessment are low and remain a challenge [24]. In our study, the size on ${ }^{18}$ FDG PET/CT was significantly different between the benign and malignant groups, but the scores of sensitivity and accuracy were poor at 55.3 and $69.3 \%$ and the diagnostic performance was significantly lower than that of either $\mathrm{SUV}_{\max }$ only or combined interpretations. This is supported by several reports that benign nodes might be enlarged as a result of benign processes such as reactive hyperplasia, obstructive pneumonia, or atelectasis, whereas metastatic nodes may appear normal in size if metastasis is present [26, 27].

Previous studies have evaluated the accuracy of oesophageal cancer lymph node staging by using PET/ CT. Hsu, et al. reported that although positive nodal FDG uptake on PET/CT was related to the pathologic findings of regional lymph node, the ability of PET/CT to predict lymph node metastasis remained inadequate [28]. Jeong, et al. also found PET/CT missed nodal metastasis detection in more than half of the patients with

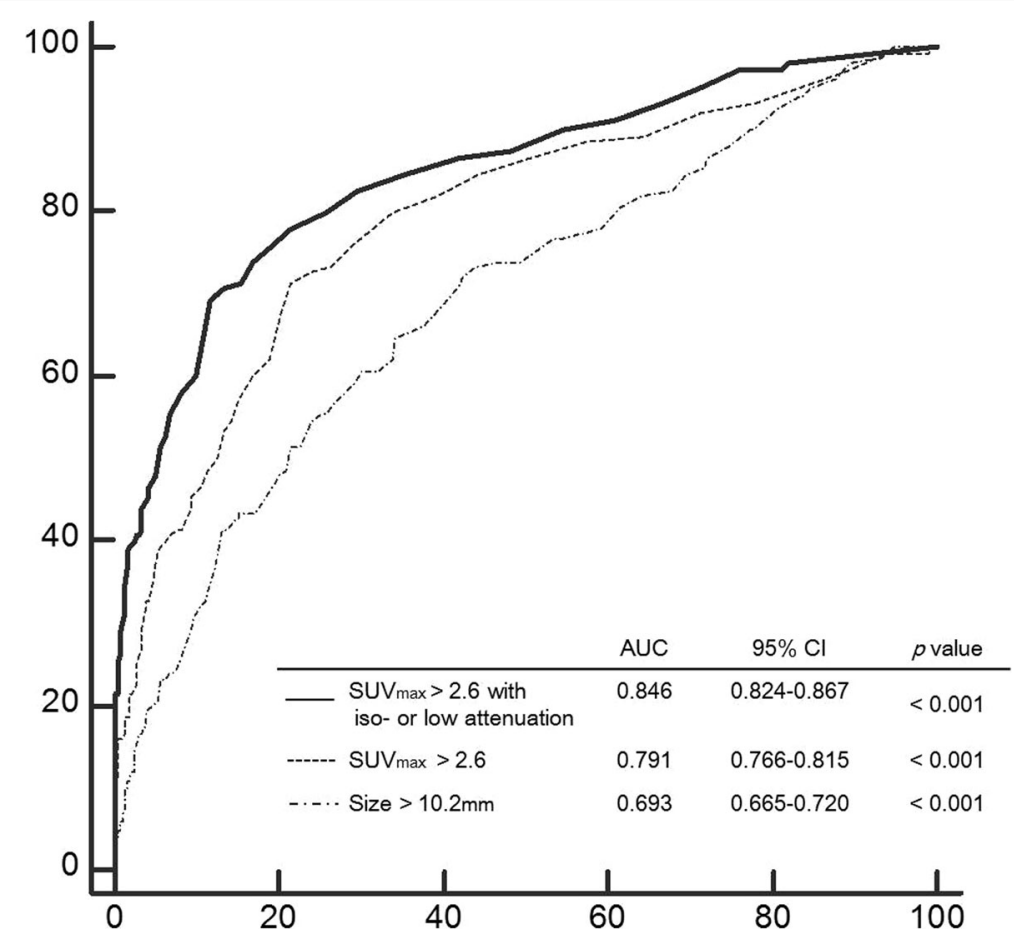

Fig. 1 ROC curve for combined interpretation, SUV max, $_{\text {and }}$ size for detecting metastatic lymph nodes in oesophageal SCC. ROC receiver operating characteristic, SCC squamous cell carcinoma, SUV max Maximum standardized uptake value 


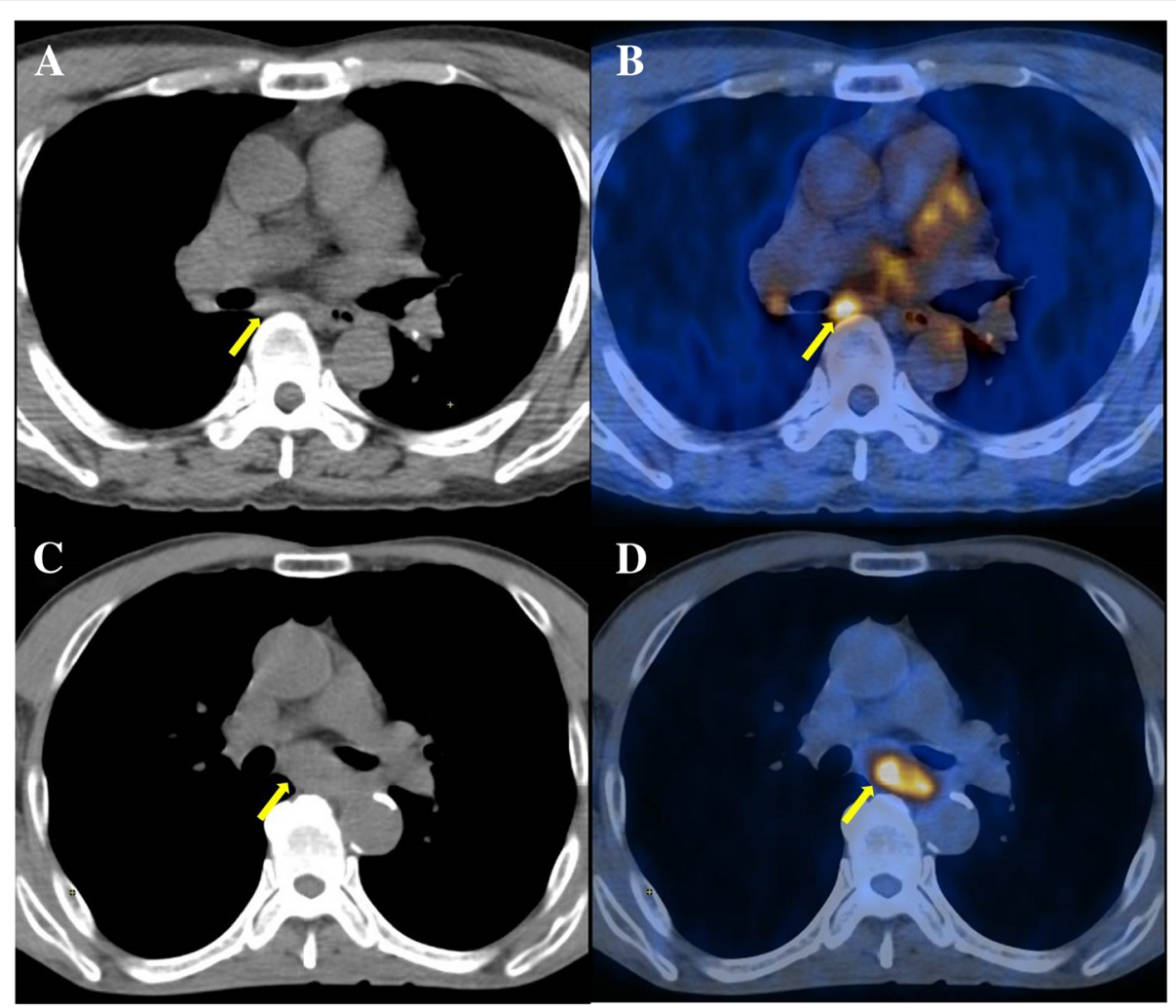

Fig. 2 PET/CT image of a 64-year-old male with oesophageal cancer showed lymph node enlargement in subcarinal area. The lymph node's CT attenuation was high as $112 \mathrm{HU}$ (a) with SUV max 4.4 (b), and this lesion was revealed to be benign lymph node after surgery. Meanwhile, PET/CT image of a 65-year-old male oesophageal cancer patient with lymph node enlargement in subcarinal area showed a low CT attenuation of $23 \mathrm{HU}$ (c) with a

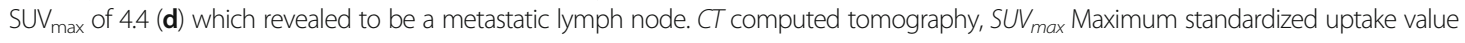

early stage oesophageal SCC [29]. A recent metaanalysis study indicated the ${ }^{18} \mathrm{~F}$-FDG PET/CT for detecting regional lymph node metastasis had a sensitivity and specificity with 95\% CI of 62\% (40-79) and 96\% (93-98) [30]. In other meta-analysis, the pooled sensitivity and specificity for PET/CT were $0.59(0.53-0.64)$ and 0.81 (0.74-0.86) [24]. Therefore, lymph node staging on PET/ $\mathrm{CT}$ is challenging because it has some limitations in the detection of regional lymph node metastasis. Our study showed a similar performance with a sensitivity and specificity of 72.7 and $76.1 \%$, retrospectively, and the ability of SUV assessment to predict node metastasis was deemed unsatisfactory. When microscopic lymph node metastasis is present, the ${ }^{18} \mathrm{~F}$-FDG uptake of the lymph node may not be increased on PET/CT, whereas inflammatory lymph nodes are shown to be falsely increased in various FDG uptakes on PET/CT, making it difficult to distinguish such from malignancy. Budiawan, et al. found that the mean $\mathrm{SUV}_{\max }$ of inflammatory/benign lymph nodes in lung cancer patient was $4.96 \pm 2.08$ (range 2.20-11.22) [31]. In Lin, et al. study, the $\mathrm{SUV}_{\max }$ of pathologically negative lymph nodes in lung cancer was $7.34 \pm 6.1$ [32]. These nodes showed follicular hyperplasia in the cortex and anthracitic pigmentation and macrophage infiltration in the medulla, and these inflammatory changes can provoke high false-positive rates and low specificity with ${ }^{18}$ F-FDG PET/CT $[18,20]$. Although 27 patients with pulmonary tuberculosis history on CT images were enrolled in the present study, these patients did not affect the results of the study.

To check the best performance of ${ }^{18}$ F-FDG PET/CT for detecting individual nodal involvement of metastasis, we included the data from the without contrast enhancement and did not include chest CT data. The noncontrast CT component of PET/CT images, which yields $\mathrm{X}$-ray attenuation values, can be helpful for characterizing lymph nodes because higher attenuations than those of mediastinal structures with/without containing calcification may be observed in inflammatory lymph nodes $[20,33]$. Therefore, several reports have suggested that lymph nodes with high attenuation and/or containing calcification on noncontrast CT images, even if they show increased FDG uptake on PET, should be regarded as benign, especially where chronic granulomatous disease is endemic $[19,20]$. However, our study revealed there was no significant difference between benign and malignant lymph nodes in terms of mean $\mathrm{HU}$, while conversely the visual attenuation pattern was significantly different 
between them. This result is discordant with those of a previous study that revealed a significant difference for mean HU between the malignant and benign lymph nodes groups [21]. This might be due to their small number of study subjects. This result is also the reason for why we considered visually high-attenuated lymph nodes as benign, unlike in previous studies which usually employed a mediastinal structure to $70 \mathrm{HU}$ criterion for the high attenuation value.

In the present study, when interpreting ${ }^{18} \mathrm{~F}$-FDG PET/ $\mathrm{CT}$, combined interpretation considering $\mathrm{SUV}_{\max }$ on PET images with visual attenuation assessment on noncontrast CT component was significantly more specific than SUVmax-only evaluation on PET images for the detection of regional lymph node metastasis without a significant difference in sensitivity. The overall diagnostic performance for the $\mathrm{SUV}_{\max }$-only method in our and previous studies was around 70\% (range: 63-73.1\%), which significantly increased to $84.5 \%$ in the combined interpretation of an $\mathrm{SUV}_{\max }$ of more than 2.6 with iso- or low CT attenuation. Kim et al., who had similar study settings, showed concordance with our study, but they couldn't obtain the optimal SUV $\mathrm{max}_{\text {ax }}$ because of PET image evaluation by visual analysis (12). They also concluded that the assignment of highly attenuated lymph nodes with increased FDG uptake as benign could improve diagnostic accuracy for metastatic lymph nodes. Therefore, performing the combined interpretation considering FDG uptake and attenuation on ${ }^{18} \mathrm{~F}$-FDG PET/CT could improve the specificity of lymph node staging of oesophageal cancer by reducing false-positives and could influence the surgical extent of lymphadenectomy, especially in populations where chronic granulomatous disease is endemic.

Our study possesses several limitations. First, it is a retrospective study and we included only patients who had underwent oesophagectomy with lymph node dissection. Thus, we might have selection bias and both the sensitivity and accuracy may have been underestimated. Second, because oesophageal adenocarcinoma is very rare in Asia including our country, this study included patients with SCC only. Therefore, further study is needed for patients with oesophageal adenocarcinoma to investigate whether our results can be applied for those patients. Third, this study was localized to a single hospital; therefore, further multicentre and prospective studies may be needed to evaluate the value of PET/CT for regional nodal metastasis in oesophageal cancer patients. Finally, because the optimal cutoff values of mean $\mathrm{SUV}_{\max }$ and size for individual lymph nodes were calculated by the sum of maximum sensitivity and specificity, the performance ability may be overestimated.

\section{Conclusions}

The diagnostic accuracy of PET/CT for nodal metastasis in oesophageal squamous cell carcinoma is improved by the combined interpretation of ${ }^{18} \mathrm{~F}$-FDG uptake and visual CT attenuation pattern. In other words, when ${ }^{18} \mathrm{~F}$ FDG-avid lymph nodes of more than a $\mathrm{SUV}_{\max }$ of 2.6 with iso- or low CT attenuation were considered as metastasis, and nodes that showed high $\mathrm{CT}$ attenuation and/or calcification were regarded as benign even if $\mathrm{SUV}_{\max }$ was 2.6 or higher, the accuracy is enhanced by reducing the false-positive rate in endemic areas of granulomatous disease. The high specificity of the combined interpretation of $\mathrm{SUV}_{\max }$ and visual CT attenuation on PET/CT images for nodal assessment may be helpful in determining therapeutic plans in patients with oesophageal SCC.

\footnotetext{
Abbreviations

${ }^{18}$ F-FDG: fluorine-18-fluorodeoxyglucose; AUC: area under the curve; $\mathrm{Cl}$ : confidence interval; EUS: endoscopic ultrasonography; HU: Hounsfield unit; MBP: mediastinal blood pool; NPV: negative predictive values; PET/ $C T$ : positron emission tomography/computed tomography; PPV: positive predictive value; ROC: receiver operating characteristic; ROI: region of interest; SCC: squamous cell carcinoma; SUV max: maximum standardized uptake value
}

\section{Acknowledgements}

None.

\section{Authors' contributions}

JYC was contributed to the conception and design of the study, interpretation of data, drafted the manuscript for publication and acted as the corresponding author. JYL and YHK contributed to design of the study, data collection, analysis, interpretation, and drafted the manuscript. HWC, YJP, and SBP participated in data collection, interpretation, analysis, and prepared the manuscript. JIZ, YMS, and KSL drafted the manuscript and reviewed the initial, final manuscript. All authors read and approved the final manuscript.

\section{Funding}

This paper was supported by the National R \& D Program for Cancer Control, Ministry of Health \& Welfare, Korea (grant number: 1720180).

\section{Availability of data and materials}

The datasets used and/or analysed during the current study are available from the corresponding author on reasonable request.

\section{Ethics approval and consent to participate}

This study was approved by the relevant Institutional Review Board (IRB no. 2019-03-129). Informed consent was waived due to the retrospective cohort study design.

\section{Consent for publication}

Not applicable.

\section{Competing interests}

The authors declare that they have no competing interests.

\section{Author details}

${ }^{1}$ Department of Nuclear Medicine, Jeju National University Hospital, Jeju National University School of Medicine, Jeju, Republic of Korea. ${ }^{2}$ Department of Nuclear Medicine, Kangbuk Samsung Hospital, Sungkyunkwan University School of Medicine, Seoul, Republic of Korea. ${ }^{3}$ Department of Nuclear Medicine, Samsung Medical Center, Sungkyunkwan University School of Medicine, 81 Irwon-ro, Gangnam-gu, Seoul 06351, Republic of Korea. ${ }^{4}$ Department of Radiology, Soonchunhyang University Seoul Hospital, Soonchunhyang University College of Medicine, Seoul, Republic of Korea. ${ }^{5}$ Department of Nuclear Medicine, Konkuk University Medical Center, Konkuk University School of Medicine, Seoul, Republic of Korea. ${ }^{6}$ Department of Thoracic and Cardiovascular Surgery, Samsung Medical Center,

Sungkyunkwan University School of Medicine, Seoul, Republic of Korea. 
${ }^{7}$ Department of Radiology, Samsung Medical Center, Sungkyunkwan University School of Medicine, Seoul, Republic of Korea.

Received: 3 April 2019 Accepted: 13 June 2019

Published online: 21 June 2019

\section{References}

1. Ferlay J, Soerjomataram I, Dikshit R, Eser S, Mathers C, Rebelo M, et al. Cancer incidence and mortality worldwide: sources, methods and major patterns in GLOBOCAN 2012. Int J Cancer. 2015;136:E359-86.

2. Zhang Y. Epidemiology of esophageal cancer. World J Gastroenterol. 2013;19:5598-606

3. Baquet CR, Commiskey P, Mack K, Meltzer S, Mishra SI. Esophageal cance epidemiology in blacks and whites: racial and gender disparities in incidence, mortality, survival rates and histology. J Natl Med Assoc. 2005:97:1471-8.

4. Hirst J, Smithers BM, Gotley DC, Thomas J, Barbour A. Defining cure for esophageal cancer: analysis of actual 5-year survivors following esophagectomy. Ann Surg Oncol. 2011;18:1766-74.

5. Miyata H, Yamasaki M, Kurokawa Y, Takiguchi S, Nakajima K, Fujiwara Y, et al. Multimodal treatment for resectable esophageal cancer. Gen Thorac Cardiovasc Surg. 2011;59:461-6.

6. Choi JY, Jang HJ, Shim YM, Kim K, Lee KS, Lee KH, et al. 18F-FDG PET in patients with esophageal squamous cell carcinoma undergoing curative surgery: prognostic implications. J Nucl Med. 2004:45:1843-50.

7. Akutsu Y, Matsubara $H$. The significance of lymph node status as a prognostic factor for esophageal cancer. Surg Today. 2011:41:1190-5.

8. Miyata H, Yamasaki M, Makino T, Tatsumi M, Miyazaki Y, Takahashi T, et al. Impact of number of [(18) F]fluorodeoxyglucose-PET-positive lymph nodes on survival of patients receiving neoadjuvant chemotherapy and surgery for oesophageal cancer. Br J Surg. 2016;103:97-104.

9. Matsubara T, Ueda M, Nakajima T. Preoperative assessment of lymph nodes in the prediction of disease spread and outcome in cancer of the thoracic oesophagus. Br J Surg. 1995:82:356-9.

10. Hosch SB, Stoecklein NH, Pichlmeier U, Rehders A, Scheunemann P, Niendorf A, et al. Esophageal cancer: the mode of lymphatic tumor cell spread and its prognostic significance. J Clin Oncol. 2001;19:1970-5.

11. Shin KE, Lee KS, Choi JY, Kim HK, Shim YM. Esophageal malignancy and staging. Semin Roentgenol. 2013;48:344-53.

12. Siewert JR, Stein HJ, Feith M, Bruecher BL, Bartels H, Fink U. Histologic tumor type is an independent prognostic parameter in esophageal cancer lessons from more than 1,000 consecutive resections at a single center in the Western world. Ann Surg. 2001;234:360-7 discussion 8-9.

13. Stein HJ, Feith M, Bruecher BL, Naehrig J, Sarbia M, Siewert JR. Early esophageal cancer: pattern of lymphatic spread and prognostic factors for long-term survival after surgical resection. Ann Surg. 2005;242:566-73 discussion 73-5.

14. Choi JY, Lee KH, Shim YM, Lee KS, Kim JJ, Kim SE, et al. Improved detection of individual nodal involvement in squamous cell carcinoma of the esophagus by FDG PET. J Nucl Med. 2000:41:808-15.

15. Kumar P, Damle NA, Bal C. Role of F18-FDG PET/CT in the staging and restaging of esophageal Cancer: a comparison with CECT. Indian J Surg Oncol. 2011;2:343-50.

16. Barber TW, Duong CP, Leong T, Bressel M, Drummond EG, Hicks RJ. 18F-FDG PET/CT has a high impact on patient management and provides powerful prognostic stratification in the primary staging of esophageal cancer: a prospective study with mature survival data. J Nucl Med. 2012:53:864-71.

17. Moon SH, Kim HS, Hyun SH, Choi YS, Zo Jl, Shim YM, et al. Prediction of occult lymph node metastasis by metabolic parameters in patients with clinically N0 esophageal squamous cell carcinoma. J Nucl Med. 2014;55:743-8.

18. Yoon YC, Lee KS, Shim YM, Kim BT, Kim K, Kim TS. Metastasis to regional lymph nodes in patients with esophageal squamous cell carcinoma: CT versus FDG PET for presurgical detection prospective study. Radiology. 2003;227:764-70.

19. Kim BT, Lee KS, Shim SS, Choi JY, Kwon OJ, Kim H, et al. Stage T1 non-small cell lung cancer: preoperative mediastinal nodal staging with integrated FDG PET/CT--a prospective study. Radiology. 2006;241:501-9.

20. Shim SS, Lee KS, Kim BT, Chung MJ, Lee EJ, Han J, et al. Non-small cell lung cancer: prospective comparison of integrated FDG PET/CT and CT alone for preoperative staging. Radiology. 2005:236:1011-9.

21. Kim SH, Lee KN, Kang EJ, Kim DW, Hong SH. Hounsfield units upon PET/CT are useful in evaluating metastatic regional lymph nodes in patients with oesophageal squamous cell carcinoma. Br J Radiol. 2012;85:606-12.
22. Korst RJ, Rusch WW, Venkatraman E, Bains MS, Burt ME, Downey RJ, et al. Proposed revision of the staging classification for esophageal cancer. J Thorac Cardiovasc Surg. 1998;115:660-9 discussion 9-70.

23. van Vliet EP, Heijenbrok-Kal MH, Hunink MG, Kuipers EJ, Siersema PD. Staging investigations for oesophageal cancer: a meta-analysis. Br J Cancer. 2008;98:547-57.

24. Sgourakis $\mathrm{G}$, Gockel I, Lyros $\mathrm{O}$, Hansen $\mathrm{T}$, Mildenberger $\mathrm{P}$, Lang $\mathrm{H}$. Detection of lymph node metastases in esophageal cancer. Expert Rev Anticancer Ther. 2011;11:601-12.

25. Xue L, Ren L, Zou S, Shan L, Liu X, Xie Y, et al. Parameters predicting lymph node metastasis in patients with superficial esophageal squamous cell carcinoma. Mod Pathol. 2012;25:1364-77.

26. Yokoi K, Okuyama A, Mori K, Tominaga K, Miyazawa N, Takizawa I, et al. Mediastinal lymph node metastasis from lung cancer: evaluation with TI-201 SPECT--comparison with CT. Radiology. 1994;192:813-7.

27. Dillemans B, Deneffe G, Verschakelen J, Decramer M. Value of computed tomography and mediastinoscopy in preoperative evaluation of mediastinal nodes in non-small cell lung cancer. A study of 569 patients. Eur J Cardiothorac Surg. 1994;8:37-42.

28. Hsu WH, Hsu PK, Wang SJ, Lin KH, Huang CS, Hsieh CC, et al. Positron emission tomography-computed tomography in predicting locoregional invasion in esophageal squamous cell carcinoma. Ann Thorac Surg. 2009;87:1564-8.

29. Jeong DY, Kim MY, Lee KS, Choi JY, Kim SJ, Chung MJ, et al. Surgically resected T1- and T2-stage esophageal squamous cell carcinoma: $\mathrm{T}$ and $\mathrm{N}$ staging performance of EUS and PET/CT. Cancer Med. 2018;7:3561-70.

30. Shi W, Wang W, Wang J, Cheng H, Huo X. Meta-analysis of 18FDG PET-CT for nodal staging in patients with esophageal cancer. Surg Oncol. 2013;22:112-6.

31. Budiawan H, Cheon GJ, Im HJ, Lee SJ, Paeng JC, Kang KW, et al. Heterogeneity analysis of (18) F-FDG uptake in differentiating between metastatic and inflammatory lymph nodes in adenocarcinoma of the lung: comparison with other parameters and its application in a clinical setting. Nucl Med Mol Imaging. 2013;47:232-41.

32. Lin WY, Hsu WH, Lin KH, Wang SJ. Role of preoperative PET-CT in assessing mediastinal and hilar lymph node status in early stage lung cancer. J Chin Med Assoc. 2012;75:203-8.

33. Takamochi K, Nagai K, Yoshida J, Suzuki K, Ohde Y, Nishimura M, et al. The role of computed tomographic scanning in diagnosing mediastinal node involvement in non-small cell lung cancer. J Thorac Cardiovasc Surg. 2000;119:1135-40.

\section{Publisher's Note}

Springer Nature remains neutral with regard to jurisdictional claims in published maps and institutional affiliations.

Ready to submit your research? Choose BMC and benefit from:

- fast, convenient online submission

- thorough peer review by experienced researchers in your field

- rapid publication on acceptance

- support for research data, including large and complex data types

- gold Open Access which fosters wider collaboration and increased citations

- maximum visibility for your research: over $100 \mathrm{M}$ website views per year

At BMC, research is always in progress.

Learn more biomedcentral.com/submissions 